\title{
Correction to: Variance of Lattice Point Counting in Thin Annuli
}

\author{
Leonardo Colzani ${ }^{1} \cdot$ Bianca Gariboldi $^{2} \cdot$ Giacomo Gigante $^{2}$ iif
}

Published online: 3 December 2020

(c) The Author(s) 2020

\section{Correction to: The Journal of Geometric Analysis https://doi.org/10.1007/s12220-020-00479-y}

The original version of the article unfortunately contained an error in the acknowledgments section. The corrected Acknowledgements is given below.

Acknowledgements The authors acknowledge support by the GNAMPA - INdAM Project 2019 "Distribuzione uniforme di punti su varietà.

Open Access This article is licensed under a Creative Commons Attribution 4.0 International License, which permits use, sharing, adaptation, distribution and reproduction in any medium or format, as long as you give appropriate credit to the original author(s) and the source, provide a link to the Creative Commons licence, and indicate if changes were made. The images or other third party material in this article are included in the article's Creative Commons licence, unless indicated otherwise in a credit line to the material. If material is not included in the article's Creative Commons licence and your intended use is not permitted by statutory regulation or exceeds the permitted use, you will need to obtain permission directly from the copyright holder. To view a copy of this licence, visit http://creativecommons.org/licenses/by/4.0/.

Publisher's Note Springer Nature remains neutral with regard to jurisdictional claims in published maps and institutional affiliations.

The original article can be found online at https://doi.org/10.1007/s12220-020-00479-y.

$凶$ Giacomo Gigante

giacomo.gigante@unibg.it

Leonardo Colzani

leonardo.colzani@unimib.it

Bianca Gariboldi

biancamaria.gariboldi@unibg.it

1 Dipartimento di Matematica e Applicazioni, Università degli Studi di Milano-Bicocca, Via R.

Cozzi 55, 20125 Milan, Italy

2 Dipartimento di Ingegneria Gestionale, dell'Informazione e della Produzione, Università degli Studi di Bergamo, Viale Marconi 5, 24044 Dalmine, BG, Italy 